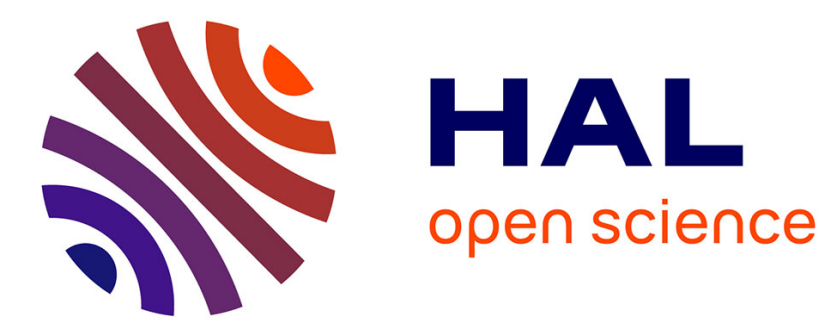

\title{
Relaxation Mechanisms in High Purity 99.999\% Aluminium at Medium Temperatures
}

\author{
M. Nó, I. Gallego, J. San Juan
}

\section{To cite this version:}

M. Nó, I. Gallego, J. San Juan. Relaxation Mechanisms in High Purity 99.999\% Aluminium at Medium Temperatures. Journal de Physique IV Proceedings, 1996, 06 (C8), pp.C8-243-C8-246. 10.1051/jp4:1996852 . jpa-00254660

\section{HAL Id: jpa-00254660 https://hal.science/jpa-00254660}

Submitted on 1 Jan 1996

HAL is a multi-disciplinary open access archive for the deposit and dissemination of scientific research documents, whether they are published or not. The documents may come from teaching and research institutions in France or abroad, or from public or private research centers.
L'archive ouverte pluridisciplinaire HAL, est destinée au dépôt et à la diffusion de documents scientifiques de niveau recherche, publiés ou non, émanant des établissements d'enseignement et de recherche français ou étrangers, des laboratoires publics ou privés. 


\title{
Relaxation Mechanisms in High Purity $\mathbf{9 9 . 9 9 9 \%}$ Aluminium at Medium Temperatures
}

\author{
M.L. Nó, I. Gallego and J. San Juan* \\ Dpto. Física Aplicada II, Fac. Ciencias, Univ. País Vasco, Apdo. 644, 48080 Bilbao, Spain \\ * Dpto. Física Mat. Condensada, Fac. Ciencias, Univ. País Vasco, Apdo. 644, 48080 Bilbao, Spain
}

\begin{abstract}
In this work we have studied the microstructural conditions for the appearance of the $\mathrm{P}_{3}$ relaxation at about $650 \mathrm{~K}$ in $99.999 \%$ Aluminium. The experimental behaviour of the $\mathrm{P}_{3}$ peak allows us to conclude that it is linked to a process of dislocation mobility.
\end{abstract}

\section{INTRODUCTION}

The internal friction (IF) spectra in Al $5 \mathrm{~N}$ single crystals was studied by Woirgard et al. [1,2] between $300 \mathrm{~K}$ and $700 \mathrm{~K}$ and decomposed in a high temperature background plus three relaxation peaks named $P_{1}, P_{2}$ and $P_{3}$. These relaxations appear also in bicrystals and an annealing at $673 \mathrm{~K}$ increases the $\mathrm{P}_{2}$ and $P_{3}$ relaxations. In polycrystals Woirgard et al. [1,2] observe so high the $P_{2}$ relaxation that the $P_{1}$ and $\mathrm{P}_{3}$ relaxations are hidden. These results were confirmed by Bonetti et al. [3], who observe in $\mathrm{Al} 4 \mathrm{~N}$ single crystals slightly deformed by flexion three relaxations $\mathrm{K}_{1}, \mathrm{~K}_{2}$ and $\mathrm{H}$ that increase with the deformation degree and do not disappear even after annealing at $813 \mathrm{~K}$ during 12 hours. These relaxations appear also in polycrystals after primary recrystallization, being much more strength than in single crystals [3,4]. On the contrary, Kê et al. [5] do not observe any relaxation between $450 \mathrm{~K}$ and $700 \mathrm{~K}$ in $\mathrm{Al} 4 \mathrm{~N}$ and $\mathrm{Al} 5 \mathrm{~N}$ single crystals grown by zone melting. Nevertheless they observe a peak around $640 \mathrm{~K}$ (named $\mathrm{P}_{365}$ ) in similar single crystals grown by dynamic annealing [5-7], but this peak disappears after a $5 \%$ creep deformation at the temperature of the peak maximum, or after a $5 \%$ tensile deformation at room temperature followed by a $2 \mathrm{~h}$ annealing at $873 \mathrm{~K}$ [7]. In the case of polycrystals of $\mathrm{Al} 4 \mathrm{~N}$ and $\mathrm{Al} 5 \mathrm{~N}$ with bamboo microstructure, these authors observe a relaxation also at $640 \mathrm{~K}$ when the sample has been deformed $3 \%$ and annealed at $830 \mathrm{~K}$. This relaxation is dependent on the oscillating amplitude [7] and dissapears by tensile deformation [8]. Using another kind of internal friction measurements, stabilizing the temperature 4 hours before each measurement, Rivière et al [9-11] observe three relaxations $\mathrm{P}_{1}, \mathrm{P}_{2}$ and $\mathrm{P}_{3}$ that are amplitude independent and besides $P_{2}$ and $P_{3}$ do not disappear even after annealing at $800 \mathrm{~K}$.

A comparative and exhaustive study of the relaxations observed in the literature in $\mathrm{Al} 6 \mathrm{~N}, \mathrm{Al} 5 \mathrm{~N}$ and Al4N at medium and high temperatures has been acomplished by Nó [12]. This study allows her to conclude that the high temperature component of the Kê peak, as well as the $\mathrm{P}_{365}, \mathrm{P}_{3}$ and $\mathrm{H}$ peaks are the same relaxation, that in the present work will be named as $\mathrm{P}_{3}$ peak.

The aim of this work is to contribute with some suplementary results about the $\mathrm{P}_{3}$ peak in order to understand its behaviour and to clarify the microscopic mechanism responsible for this relaxation.

\section{EXPERIMENTAL CONDITIONS}

In the present work we used 99.999\% Aluminium (5N) "super raffinal" AIAG. The $5 \mathrm{~N} \mathrm{Al} \mathrm{supplied}$ in $10 \mathrm{~mm}$ plates was rolled until it was $1.1 \mathrm{~mm}$ thick and annealed under primary vacuum for $1 \mathrm{~h}$ at $500 \mathrm{~K}$ in order to recrystallize the samples, that were subsequently aged for a long time at room temperature. In this condition the samples show a mixed microstructure of tangled dislocations and polygonization walls. In order to obtain a polygonized dislocation structure the samples were crept [12]. This microstructure disappears during heating until $700 \mathrm{~K}$ at $100 \mathrm{~K} / \mathrm{h}$, because the samples recrystallize. After this recrystallization, the samples do not show any polygonized structure and the grain size is about $\phi=2 \mathrm{~mm}$. The study of the $P_{3}$ peak was carried out on these samples $\left(50 \times 5 \times 1 \mathrm{~mm}^{3}\right)$. Internal friction was measured using an inverted torsion pendulum operating at about $1 \mathrm{~Hz}$ with an oscillating amplitude of $4 \times 10^{-6}$. All IF spectra have been measured only on heating, at a heating rate of $100 \mathrm{~K} / \mathrm{h}$. 


\section{RESULTS AND DISCUSSION}

The internal friction spectrum of a recrystallized sample as described previously, corresponds to curve 1 in fig. 1 and shows a $\mathrm{P}_{2}$ relaxation about $550 \mathrm{~K}$ and a relatively flat high temperature background.

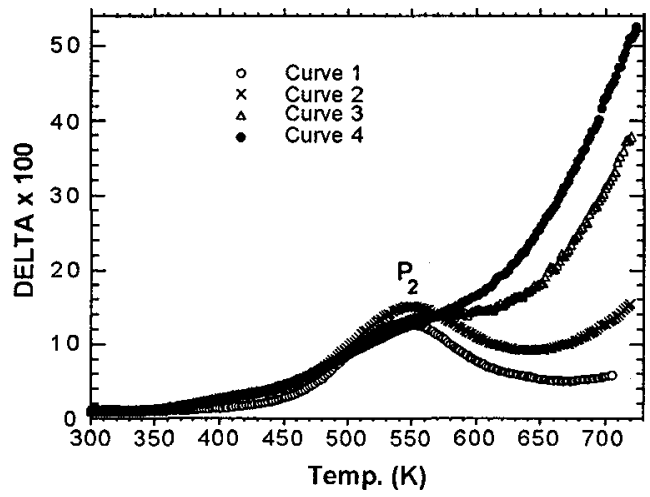

Fig. 1. Internal friction after cumulative torsional deformation at room temperature.

Before deformation (curve 1) and after a total deformation of $\pm 0.5 \%$ (curve 2 ), $\pm 2 \%$ (curve 3 ) and $\pm 8 \%$ (curve 4 ).

In order to study the influence of deformation degree on the internal friction spectrum, the sample has been deformed in torsion at room temperature by cumulative steps of $\pm 0.5 \%, \pm 1.5 \%, \pm 2 \%, \pm 4 \%$ and sucessive steps of $\pm 4 \%$ until a total deformation of $\pm 16 \%$. For a better visual clarity we plot in Fig.1 (curves 2 to 4 ) only the internal friction spectra corresponding to the total deformation of $\pm 0.5 \%, \pm 2 \%$ and $\pm 8 \%$. We observe that the high temperature background increases with the deformation percentage until a degree of $8 \%$, and shifts the more and more towards low temperature. Simultaneously, a slight decrease of the $\mathrm{P}_{2}$ relaxation can be observed. Further cumulative deformations by $\pm 4 \%$ steps do not affect the background and the obtained internal friction spectra were almost superposed on the curve 4 of Fig. 1 .
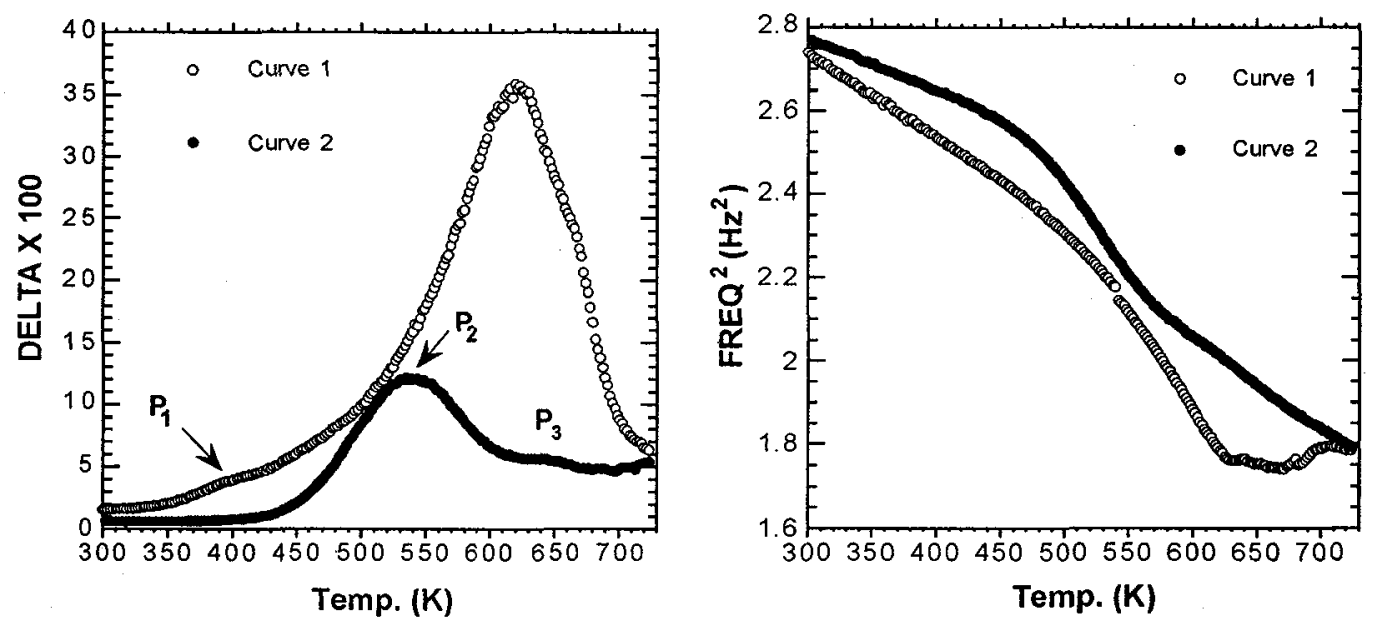

Fig. 2. Internal friction spectra and modulus defect on the same sample previously deformed $\pm 16 \%$ (see fig. 1 ).

Curve 1: after a new $\pm 12 \%$ torsional deformation performed at room temperature. The sample recrystallize again between 625 and $700 \mathrm{~K}$. Curve 2: after recrystallization we observe the $P_{2}$ peak and the appearance of the $P_{3}$ peak. 
Nevertheless, a further high deformation of $\pm 12 \%$ performed in one step at room temperature gave rise to the recrystallization of the sample between $652 \mathrm{~K}$ and $700 \mathrm{~K}$ during the measurement heating run, as is shown in the internal friction spectrum and modulus defect of curves 1 in Fig.2. The curve 2 of Fig. 2 corresponds to the first spectrum after recrystallization and shows two relaxations $P_{2}$ and $P_{3}$ that can be also seen in the associated modulus curve. These two relaxations $\mathrm{P}_{2}$ and $\mathrm{P}_{3}$ became stable during sucessive heating runs until $730 \mathrm{~K}$ as is shown in Fig.3.
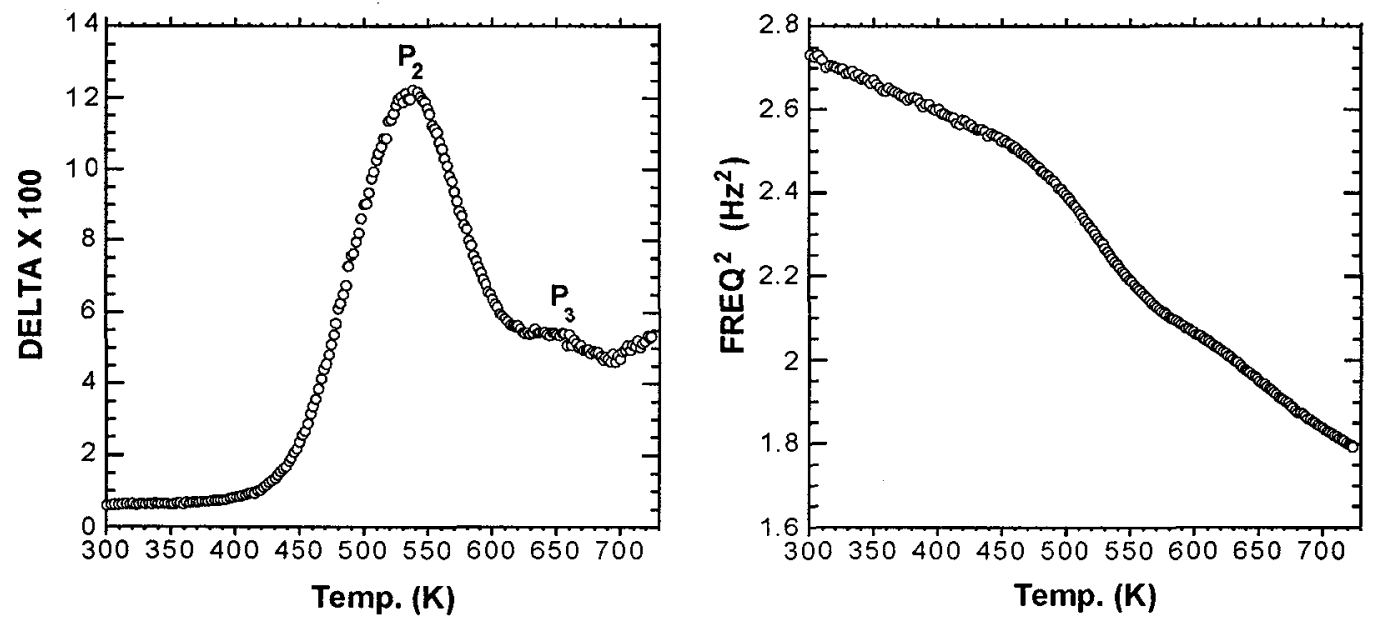

Fig. 3. Internal friction spectrum and modulus defect of stable $P_{2}$ and $P_{3}$ relaxation.

These results can be explained as follows. The original sample with a microstructure mainly with tangled dislocations presents the $\mathrm{P}_{2}$ peak that shows a similar behaviour to the $\mathrm{P}_{1}$ peak observed in $\mathrm{Al} 6 \mathrm{~N}$ $[13,14]$, and seems to be linked to a high jog density on dislocations $[1,15,16]$. The torsional deformation performed in succesive steps increases the dislocation density, but during the measurement heating runs until 730K the dislocations reorganize in polygonization walls, like it has been also observed for the $\mathrm{Al} 6 \mathrm{~N}$ $[12,14]$. This way, the high temperature background increases with the density of polygonized dislocations because in fact it is the low temperature side of a $\mathrm{P}_{\mathrm{H}}$ peak that appears at higher temperature and attributed to the mobility of the subgrain boundaries $[12,13,15,17]$. At the same time we observe a slight decrease of the $\mathrm{P}_{2}$ peak due the loosing of jogs by the dislocations during the polygonization process $[12,16]$. It should be remarked that after strong deformation, the internal friction spectrum (curve 1 of Fig. 1) shows the presence of the $P_{1}$ peak, that usually appears only in Al6N [12]. This effect is due to the increase of dislocation density and their depinning from the impurities during the deformation, that produces some non negligible dislocation density completely free of impurities. However, the recrystalization undergone (Fig.2) by the sample destroys completely the polygonized microstructure and the high temperature background recovers its original level (like in curve 1 of Fig.1) due to desappearance of the $P_{H}$ peak. Nevertheless a high density tangled dislocation microstructure remains in the sample and the $\mathrm{P}_{2}$ peak recovers its original strength. It is in this microstructural condition when the $P_{3}$ peak is clearly seen.

In order to characterize the behaviour of the $\mathrm{P}_{3}$ relaxation we have studied its evolution with the oscillating amplitude. In Fig. 4 we plot the internal friction spectra and modulus variation curves corresponding to the oscillating amplitudes of $4,8,16$ and $32 \times 10^{-6}$. From Fig.4, it becomes evident that the $\mathrm{P}_{3}$ peak shows a strong dependence on the oscillating amplitude. The previous results allows to conclude that the $\mathrm{P}_{3}$ relaxation is due to some mechanism of dislocation mobility and the associated modulus defect curves (in Fig.4) suggest that this relaxation could be linked to the same dislocations responsible for the $\mathrm{P}_{2}$ peak. 

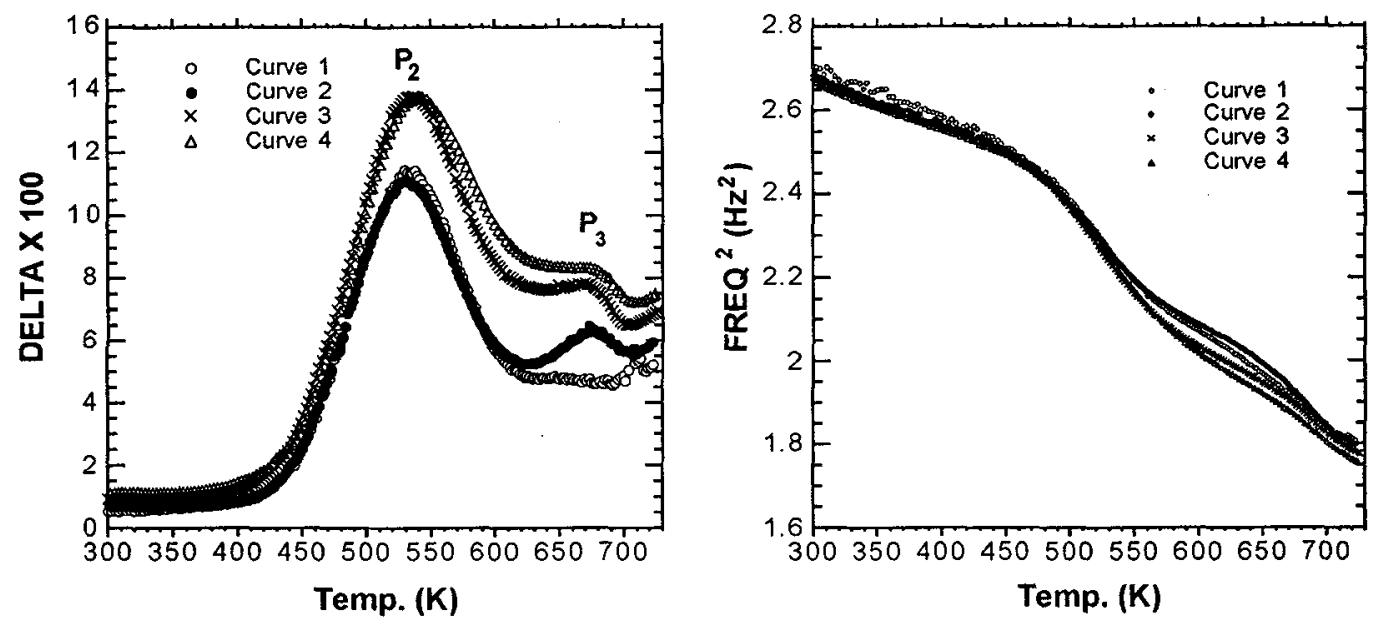

Fig. 4. Evolution of the $\mathrm{P}_{3}$ relaxation as a function of the oscillating strain amplitude.

Curve 1: $\varepsilon_{\mathbf{m}}=4 \times 10^{-6}$. Curve $2: \varepsilon_{\mathbf{m}}=8 \times 10^{-6}$. Curve $3: \varepsilon_{\mathbf{m}}=16 \times 10^{-6}$. Curve $4: \varepsilon_{\mathbf{m}}=32 \times 10^{-6}$.

\section{Acknowledgements}

This work has been carried out with the financial support of the "Universidad del Pais Vasco" (Project Number UPV 060.123-EA 178/94) and the "Gobierno Vasco" (Project number PI 95/105). I. Gallego wishes to acknowledge the "Gobierno Vasco" for providing him a postgraduate grant.

\section{References}

[1] J. Woirgard, thesis University of Poitiers (France) (1974)

[2] J. Woirgard, J.P. Amirault, J. de Fouquet, ICIFUAS vol. 1, Springer-Verlag (1975) 392

[3] E. Bonetti, E. Evangelista, P. Gondi, R. Tognato, Phys. Stat. Sol. (a) 39 (1977) 661

[4] T.S. Kê, P. Cui, C.M. Su, Phys. Stat. Sol. (a) 84 (1984) 157

[5] C.M. Su, T.S. Kê, J. de Phys. 46 (1985) 359

[6] C.M. Su, T.S. Kê, Phys. Stat. Sol. (a) 94 (1986) 191

[7] A. Rivière, thesis University of Poitiers (France) (1984)

[8] A. Rivière, J.P. Amirault, J. Woirgard, J. de Phys. 42 (1981) C5-439

[9] A. Rivière, J. Woirgard, J. de Fouquet, J. de Phys. 46 (1985) C10-343

[10] E. Bonetti, E. Evangelista, R. Gondi, R. Tognato, Il Nuovo Cimento 33B (1976) 408

[11] C.M. Su, T.S. Kê, Acta Met. 37 (1989) 79

[12] M.L. Nó, thesis University of Pais Vasco (Spain) (1990)

[13] M.L. Nó, C. Esnouf, J. San Juan, G. Fantozzi , Acta Met. 36 (1988) 827-836 and 837-845

[14] M.L. Nó, J. San Juan, C. Esnouf, Materials Science and Engineering A 113 (1989) 281-285

[15] M.L. Nó, J. San Juan, Materials Science and Engineering A 164 (1983) 153-158

[16] M.L. Nó, J. San Juan, J.I. Pérez-Landazabal, C. Esnouf, Materials Science Forum 119-121 (1993) 255-260

[17] J. Friedel, Colloque de Frottement Intérieur IRSID (Saint-Germain-en-Laye) 13-14 Oct. 1970 